\title{
A Problem of Particulate Contamination in an Automated Assembly Machine Successfully Solved by CFD and Simple Experiments
}

\author{
Jatuporn Thongsri \\ Computer Simulation in Engineering Research Group, College of Advanced Manufacturing Innovation, \\ King Mongkut's Institute of Technology Ladkrabang, Bangkok 10520, Thailand
}

Correspondence should be addressed to Jatuporn Thongsri; jatuporn.th@kmitl.ac.th

Received 12 May 2017; Revised 3 July 2017; Accepted 1 August 2017; Published 6 September 2017

Academic Editor: M. L. R. Varela

Copyright (C) 2017 Jatuporn Thongsri. This is an open access article distributed under the Creative Commons Attribution License, which permits unrestricted use, distribution, and reproduction in any medium, provided the original work is properly cited.

\begin{abstract}
Assembly of hard disk drives (HDDs) needs to be done in an automated assembly machine (AAM) virtually free of particulate contamination that can cause them to malfunction. Fan filter units (FFUs) are installed above the AAM to reduce the number of suspended particles in the recirculating air flowing over and around them. At one time, several HDDs were found to be defective. To find out the root cause of this problem, computational fluid dynamics (CFD) was used to investigate the airflow over and around the AAM. It was found that the cause of the high particle counts was improper air speed from the FFUs. The optimal FFUs air speed needed to be in the range of $0.35-0.65 \mathrm{~m} / \mathrm{s}$ in which the airflow would block out nearby airborne particles and purge away particles generated by the AAM effectively which would, in effect, reduce the particle counts down below the threshold level of class 100 clean room. A few available measurement tools at the factory were then used to perform validating measurements against the simulation results, and the validation was positive. This optimal speed range was implemented at the factory after which the level of contamination was reduced to an acceptable level.
\end{abstract}

\section{Introduction}

Thailand is a big producer of various electronics parts including hard disk drive (HDD). A major technical issue in manufacturing HDDs is particulate contamination. Since the slider head and spinning disk are only $3-10 \mathrm{~nm}$ apart during reading and writing operations, relatively big microparticles generated during the manufacturing process may lodge onto the disk and cause erroneous readings and writings. Hence, assembly of smaller parts into a fully functional HDD absolutely needs to be done in a clean room with very low airborne microparticle counts. For example, manufacturing of head stack assembly (HSA), a major component of HDD, is required to be done in class 100 of clean room. As defined in ISO class 6 of US FED STD 209E [1], this type of clean room allows no more than 100 airborne particles bigger than or equal to $0.5 \mu \mathrm{m}$ in $1 \mathrm{ft}^{3}$ of air in the room. However, class 100 clean room is prohibitively costly to construct and very difficult to maintain; therefore, in real HDD production line, class 1,000 clean room equipped with fan filter units (FFUs) is employed instead. To reduce particle counts in the air above and around assembly machines (including automated assembly machine (AAM) that welds small electronic boards to the head gimbal assembly (HGA) of HSA in an HDD production line), FFUs blow away particles from them and recirculate clean air over them $[2,3]$. This study was a collaborative research between the author and a few engineers at an HDD factory for the purpose of seeking out a solution for a problem of excessive particle contamination in some HDDs fabricated by the AAM at one time. The author had proposed using CFD simulation to find a solution for the problem because direct experiment was impractical and CFD simulation had already been proven to be reliable in many types of investigation.

Since the 1970s, CFD has been widely used to investigate airflow in various types of rooms, facilities, equipment, devices, and environments [4-13], but it has only been used for a few direct investigations of airflow over and around pieces of industrial machinery. Results from those investigations were very beneficial to our work and some are 
mentioned here. The following are examples where CFD has been used for various purposes: an investigation of the effect of the size of smoke particles on their individual trajectory inside a vertical laminar clean room [14]; a simulation of the airflow inside a hospital operating room that led to a successful reduction of the level of contamination that, if left unaddressed, might be harmful to patients undergoing an operation in the room [15-17]; a simulation of airflow and dust control in a laneway of coal mine to provide suitable guidance for the ventilation system of emergency rescuing [18]; an evaluation of the performance of air cleaners and ventilation system of a small lecture room in order to find a way to reduce particle counts in the air inside [19]; a simulation of trajectories that small particles moved along inside an HDD in order to find the best location for placing a circulating air filter [20, 21]; a formulation of a method for controlling the level of particle contamination in a clean room for manufacturing LCD screens [22]; a solution to resolve a water condensation problem in a production line of HDD factory [23]; and an aid for a design of a wafer-making machine in a semiconductor manufacturing line that reduced particle contamination [24]. One of the previous studies successfully applied CFD to find the optimal air speed from FFUs that, after implemented, was able to reduce the level of particulate contamination on HDD parts fabricated by a welding automation machine (WAM) in an HDD factory [25]. It was a preliminary investigation that had not attempted to find the root cause of the contamination or make a comparison between the simulated results and actual measurements. This research was intended as the practical solution. This CFD investigation focused on the contamination problem of the AAM, finding the root cause of the particle contamination, validating the simulated results with the actual measurements at the factory, and seeking an effective solution to the problem. In addition, for our experiments, we purposely opted for the measurement tools that were readily available at the factory at that time so that the technicians there would be able to apply our experimental procedure easily and rapidly.

\section{Theoretical Background}

Airflow pattern inside the microenvironment of an AAM was determined by solving a system of partial differential conservation and turbulence equations described in the user's guide of Ansys Fluent 17.1 software [26]. The conservation equations of mass (1), momentum (2), and energy (3) can be expressed by

$$
\begin{aligned}
& \frac{\partial \rho}{\partial t}+\frac{\partial\left(\rho u_{i}\right)}{\partial x_{j}}=0, \\
& \frac{\partial\left(\rho u_{i}\right)}{\partial t}+\frac{\partial\left(\rho u_{i} u_{i}\right)}{\partial x_{j}} \\
& =-\frac{\partial P}{\partial x_{i}}+F_{i}+\frac{\partial\left[\tau_{i j}\right]}{\partial x_{j}}+\frac{\partial\left(-\rho \overline{u_{i}^{\prime} u_{j}^{\prime}}\right)}{\partial x_{j}}+\frac{\partial\left(-\rho \overline{u_{i}^{\prime 2}}\right)}{\partial x_{i}} \\
& \quad+S_{m},
\end{aligned}
$$

$$
\begin{aligned}
& \frac{\partial(\rho E)}{\partial t}+\frac{\partial\left[u_{i}(\rho E+P)\right]}{\partial x_{i}} \\
& =\frac{\partial\left((k)_{\mathrm{eff}}\left(\frac{\partial T}{\partial x_{j}}\right)+u_{i}\left(\tau_{i j}\right)_{\mathrm{eff}}\right)}{\partial x_{j}}+S_{h} .
\end{aligned}
$$

The turbulence model used in this work is transition shear-stress transport (SST). It consists of four transport equations to represent the turbulent properties of the flow. These equations include 4 parameters: turbulence kinetic energy $(k)$, specific dissipation rate $(\omega)$, intermittency $(\gamma)$, and transition momentum thickness Reynolds number $\left(R_{e \theta}\right)$ that have to be set. The full forms of the 4 equations containing these parameters can be found in [26]. The Fluent CFD software solves (1)-(3) together with the 4 equations mentioned above to determine the airflow pattern.

The particle trace was calculated from a particle-force balance equation in the discrete phase model (DPM) in Fluent [27]:

$$
\frac{d u_{p}}{d t}=F_{D}\left(u_{f}-u_{p}\right)+g \frac{\left(\rho_{p}-\rho_{f}\right)}{\rho_{p}}+F_{s},
$$

where $F_{s}$ stands for forces that act on the particle such as rotational force, pressure gradient force, thermoelectric force, and Brownian force. These forces do not significantly affect micron-sized particles with $\rho_{p} \gg \rho_{f}$; therefore, only drag force and Saffman's lift force were taken into account in our simulation. Saffman's lift force [28] or lift due to shear can be written by

$$
\vec{F}=\frac{2 K \rho_{f} \nu^{1 / 2} d_{i j}\left(\vec{u}_{f}-\vec{u}_{p}\right)}{\rho_{p} d_{p}\left(d_{l k} d_{k l}\right)^{1 / 4}},
$$

where $K$ is 2.594 and $d_{i j}$ is the deformation tensor.

A dispersed two-phase flow model was used to simulate particle traces. It took into account the interparticle spacing of the system, $L / d_{p}$. The type of contaminating particles that we chose to simulate was aluminum particles because they were most frequently found in the HDD factory. Their diameter was set to be $0.5 \mu \mathrm{m}$, and the density was set at $2,719 \mathrm{~kg} / \mathrm{m}^{3}$ which was approximately three orders of magnitude higher than that of air $\left(1.225 \mathrm{~kg} / \mathrm{m}^{3}\right)$. The length scale $L$ for the smallest element of our mesh model was set at $2.5 \times 10^{-5} \mathrm{~m}$. All of these settings resulted in a value of 50 for the $L / d_{p}$ term. According to a conclusion by Utikar et al. [29], fluid phase and solid phase could be considered uncoupled if the value of $L / d_{p}$ was less than 100; therefore, only one-way simulation was needed for our problem. Our simulation was done with Fluent software. The transition SST model was selected as the turbulence model. This model has been widely used in the HDD industry [30]. After the airflow pattern was determined, simulated particles were released into the airstream and their trajectories were calculated. With this careful and methodical selection of simulation method and settings, we believed that the results would be sufficiently reliable for our purpose. 


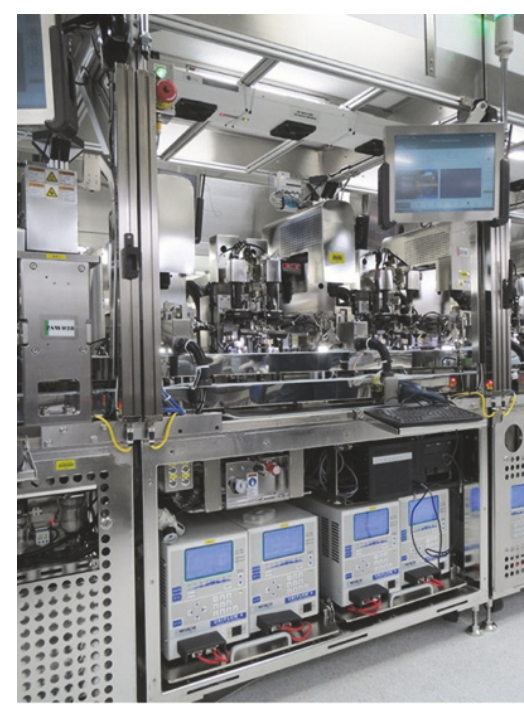

(a)

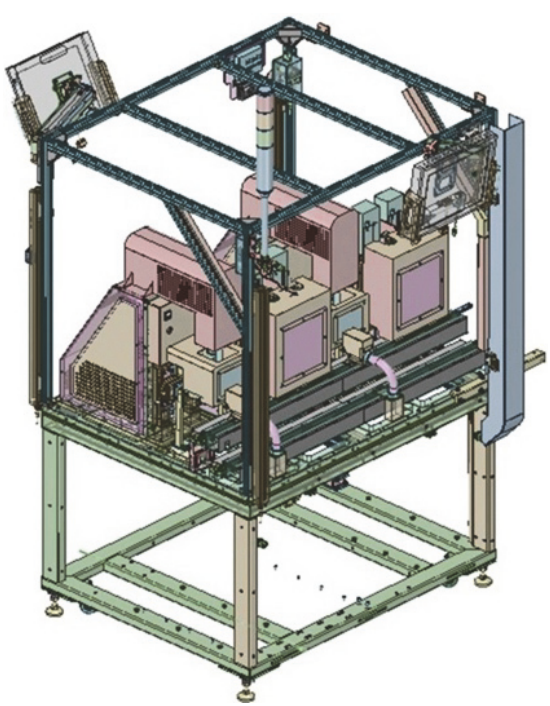

(b)

FIGURE 1: Automated assembly machine: (a) the actual machine and (b) a solid model.

\section{Methodology}

3.1. Automated Assembly Machine (AAM). The AAM investigated in this study operated as an automated welder of small electronic circuits to the HGA of HSA, a major component of HDD. The AAM within has a computer system and a mobile mechanic arm. This AAM was located in a production line inside a class 1,000 clean room in the factory. Figure 1(a) shows the actual AAM and Figure 1(b) a solid model of the AAM without FFUs above it.

An FFU is a type of ventilation equipment in the shape of a rectangle of many sizes according to its usage. In this research, the size is approximately $0.60 \mathrm{~m} \times 1.00 \mathrm{~m} \times 0.30 \mathrm{~m}$. The top side has an opening for the fan placed inside to ventilate air from above down below. The air speed exiting from the FFU can be controlled by setting the fan's speed. Within the FFU is also a HEPA filter, resulting in the exiting air that is laminar flow. The highly efficient HEPA filter, as defined by the United State Department of Energy (DOE), can filter particles sizes $0.3 \mu \mathrm{m}$ at least $99.97 \%$. Laminar flow is necessary for manufacturing since it can block out and purge away particles during the manufacturing process better than turbulent airflows.

The AAM consisted of 3 main parts: FFUs that blew filtered air over its microenvironment, pieces of assembling machinery, and a conveyor that carried electronic circuits, HGA, and finished product of HSA. Simplified from the AAM model in Figure 1, a working solid model of the AAM and the main airflow directions are illustrated in Figure 2.

3.2. Fluid and Mesh Models. We wanted to be able to track simulated particles as they were moving inside and outside of the AAM microenvironment; therefore, a fluid model and a mesh model were constructed, shown in Figures 3(a) and 3 (b), respectively. Inside the microenvironment, the mesh model was made up of tetrahedron and hexahedron meshes,

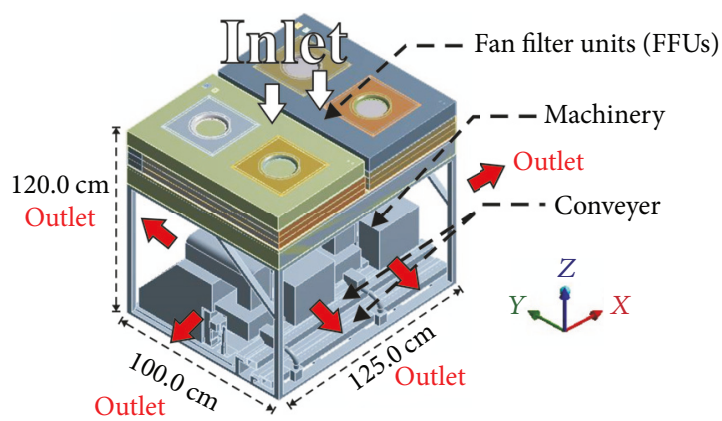

FIgURE 2: A model of the AAM showing directions of airflow.

but only hexahedron meshes were used outside of it. The dimensions of the air inlet were $100 \times 125 \mathrm{~cm}^{2}$ and those of the air outlets were $120 \times 100 \mathrm{~cm}^{2}$ and $120 \times 125 \mathrm{~cm}^{2}$. As for the global mesh control settings, the minimum mesh size, maximum face size, and maximum mesh size were assigned values of $0.05 \mathrm{~mm}, 36 \mathrm{~mm}$, and $72 \mathrm{~mm}$, respectively, with a growth rate of 1.2 and $y^{+} \sim 2$. Mesh-independent analysis was performed by varying the size of the meshes at the air inlet and outlet in the range of $1-4 \mathrm{~cm}$. The mesh size at the conveyor area was set to be $1 \mathrm{~cm}$. The optimum mesh model, both in accuracy and computation time, was found to be consisted of 1.15 million nodes and 5.24 million.

3.3. Settings of Condition Parameters. Simulation parameters were set to correspond closely with the measured ambient conditions and FFUs air speed at the HDD factory at the time that the contamination had happened. These parameter settings were the following: pressure at $106,300 \mathrm{~Pa}$, temperature at $24.5^{\circ} \mathrm{C}$, and FFUs air speed at the inlet at $0.60 \mathrm{~m} / \mathrm{s}$ (an average of a speed range of $0.50-0.70 \mathrm{~m} / \mathrm{s}$ ). These set values resulted in a nominal air change rate $(\mathrm{ACH})$ of $3,564 \mathrm{~h}^{-1}$ and a 


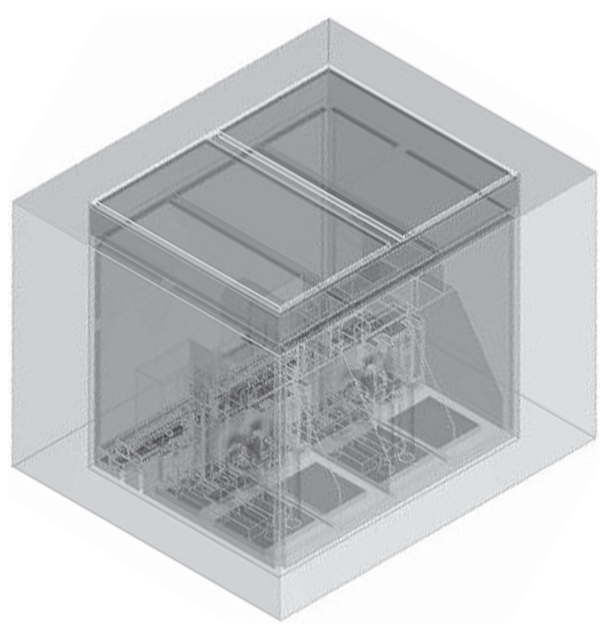

(a)

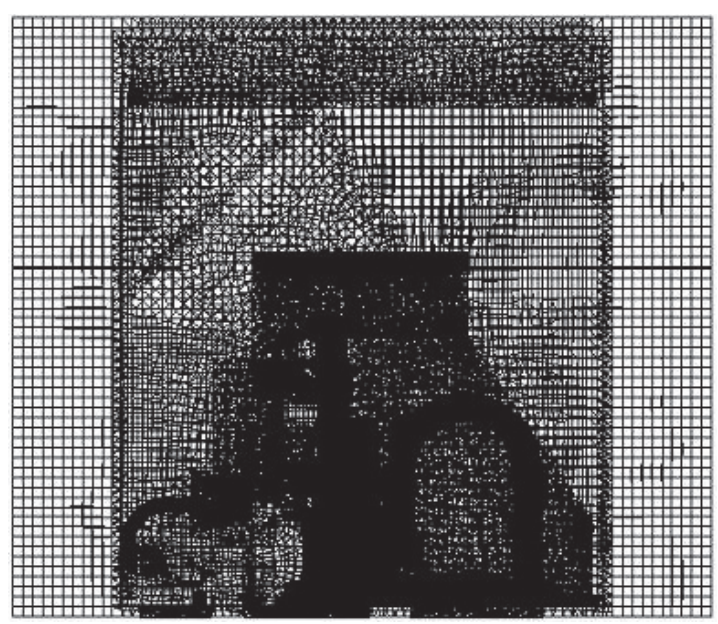

(b)

Figure 3: Models of the AAM: (a) fluid model and (b) a side view of the mesh model.

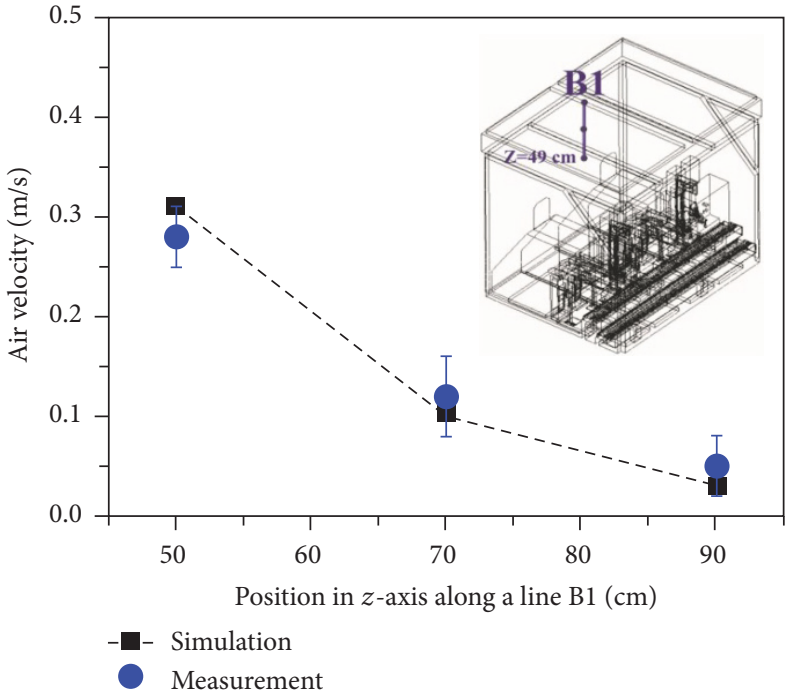

(a)

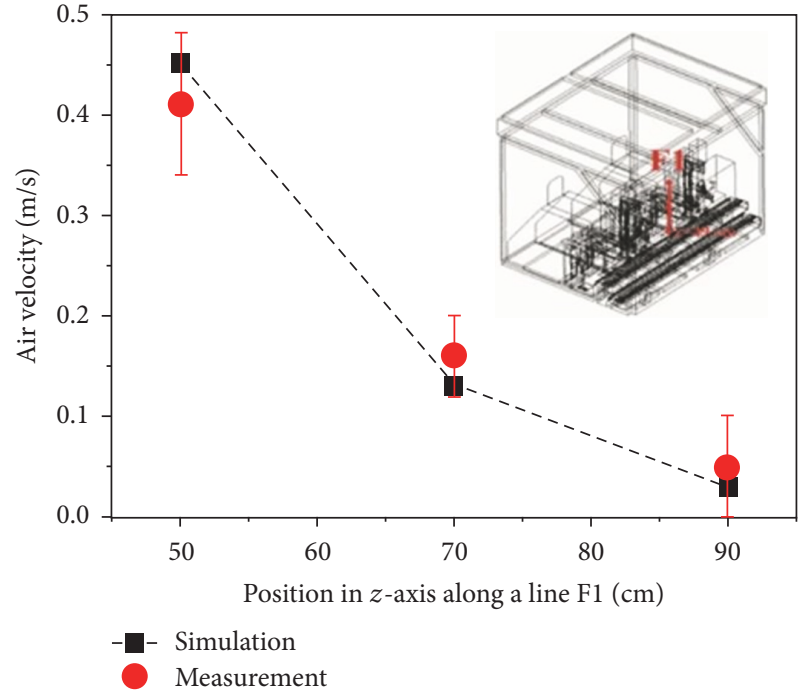

(b)

FIgURE 4: Comparison between the simulated and measured air velocities at 3 positions at (a) the back-side surface and (b) the front-side surface of the microenvironment of the AAM.

pressure difference at the outlet of $0 \mathrm{~Pa}$. The pressure-velocity coupling was set to coupled, and the spatial discretization of pressure, momentum, turbulent kinetic energy, and turbulent dissipation rate were set to be second-order upwind. All other parameters were set to default. Steady state calculation was repeated until the solution converged.

3.4. Validation. One of the best ways to observe airflow pattern in a clean room is to perform a smoke visualization test. However, we were not able to do so because $\mathrm{CO}_{2}$ and $\mathrm{H}_{2} \mathrm{O}$ vapors as well as those of other liquids used for this purpose might condense on the AAM and other pieces of machinery in the room and cause incalculable damage. Hence, instead of validating our simulation results with observed airflow pattern, we chose to validate them by showing that the simulated airflow velocities and directions at key places in the microenvironment of the AAM matched the actual ones closely. The actual air velocities were measured with a $\pm 0.03 \mathrm{~m} / \mathrm{s}$-accurate hot-wire anemometer. We measured the air velocities flowing perpendicularly through 18 points at the front-side and back-side outlets while the AAM was working, three points on each of the 3 chosen imaginary lines on the surface of each outlet. At each point, twenty measurements were made and the average value was calculated. The simulated air velocities at the same positions were obtained from Fluent software by using the mesh model in Figure 3(b). It was found that the simulated air velocities and directions matched closely with the actual ones at all key places. As an example, Figure 4 shows the simulated and measured air velocities at 3 points along the imaginary lines 


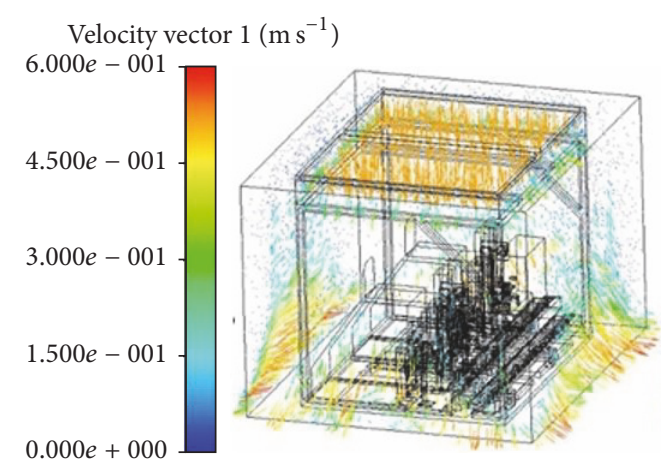

(a)

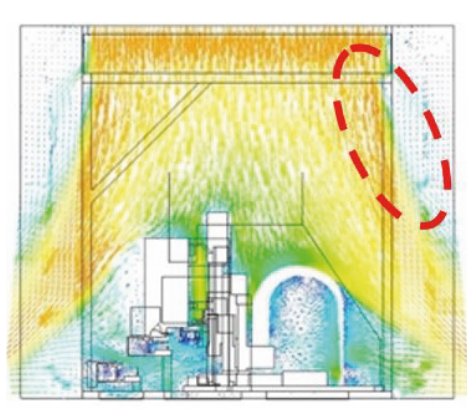

(b)

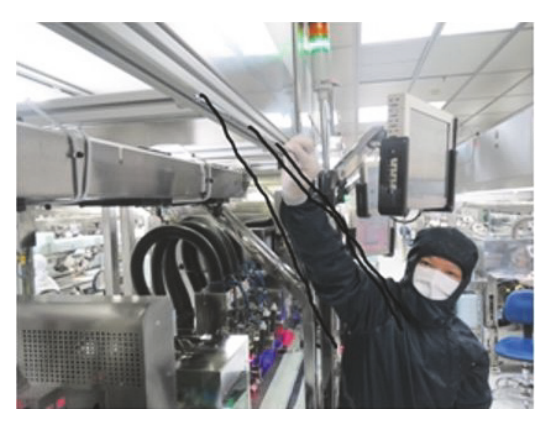

(c)

FIgURE 5: Velocity vectors of the airflow inside the AAM microenvironment: (a) a full view, (b) a view of a section plane near to a side, and (c) positions on the actual AAM to which some threads were attached.

$\mathrm{B} 1$ and $\mathrm{F} 1$ at (a) the back-side outlet surface and (b) the frontside outlet surface of the microenvironment, respectively. It can be clearly seen that they were closely matched. The small errors might be due to our using a constant FFUs air speed of $0.60 \mathrm{~m} / \mathrm{s}$ to represent the real inconstant FFUs air speeds in the range of $0.50-0.70 \mathrm{~m} / \mathrm{s}$. The actual airflow directions were determined by observing the directions that special sewing threads were oriented in the airstream. One end of the threads was attached to the surface of each of the key locations around the AAM. This special type of thread is usually used for testing electrostatic discharge (ESD) in a clean room. It is made of conductive polyester yarn that is very light (only 60\% as dense as regular thread), so its free end moves freely in an airstream. Figures 5(a) and 5(b) show simulated air velocity vectors inside the AAM microenvironment at the FFUs air speed setting of $0.60 \mathrm{~m} / \mathrm{s}$. Figure 5(a) shows a full view of the model while Figure 5(b) shows a view of a section plane near a side of the AAM. It can be clearly seen that the simulated airstream flowed down from the FFUs over the AAM and then moved along and out through the outlets at all four sides in the same directions as the actual airflow directions observed at the factory. Figure 5(c) shows a photo of several locations on the AAM where the threads were attached. The size of the threads was exaggerated to make them visible in the photo.

The comparison between the airflow near the marked area in Figure 5(b) compared to the flow direction of sewing threads in Figure 5(c) shows conformation; the air in the marked area makes the sewing threads flow out of the AAM in a systematic pattern without any random crisscross patterns as found in turbulent air. The close matches of simulated and measured air velocities and directions at all key places validated that our simulation was sufficiently reliable.

Another piece of supporting evidence for the reliability of our simulation was that one of the simulated results was positively confirmed by actual occurrences at the factory. This result indicated that particles would get trapped on the conveyor at higher FFUs air speeds. It was indirectly confirmed by a report from a technician at the factory that the level of contamination in the fabricated products became unacceptably high at higher FFUs air speed settings. These

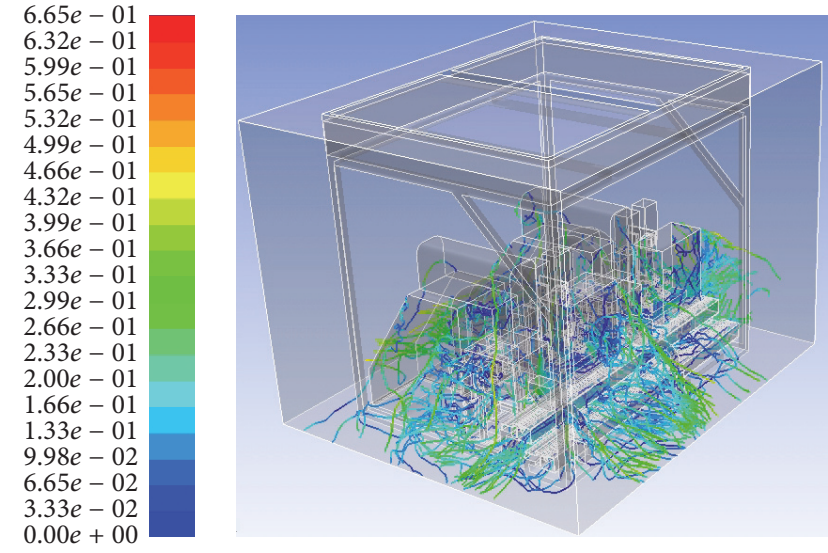

FIgURE 6: Traces of 300 particles released inside the AAM and carried by the airflow, color coded according to each particle residence time (s).

occurrences are discussed further in the light of our findings in Results and Discussion.

\section{Results and Discussion}

4.1. Optimum FFUs Air Speed: Contamination on the Conveyor. In order to find out how some pieces of products fabricated by the AAM at the factory got contaminated when the FFUs air speed was set at $0.60 \mathrm{~m} / \mathrm{s}$, we simulated releases of 300 spherical aluminum particles from various locations on the machine into the airstream. As can be seen in Figure 6, the simulated result shows that most of the particles got carried away through the outlets at all 4 sides of the microenvironment, but a small number of particles got pushed onto the conveyor and contaminated it. This simulation confirms a contamination problem in the AAM. We also simulated releases of larger numbers of particles at different FFUs air speeds in a slightly lower but more extended range in order to find the optimum speed that provided the least contamination. The simulation process and results are described in detail as follows. 

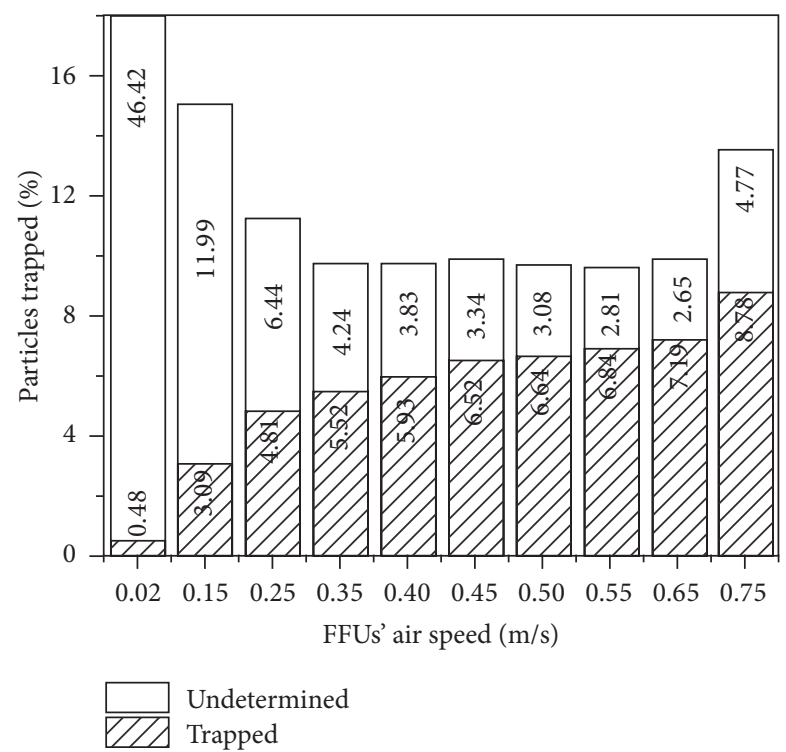

Figure 7: Percentages of aluminum particles trapped on the conveyor at different FFUs air speeds.

We wanted to know the influence of FFUs air speed on the level of contamination on the conveyor, so we simulated releases of 3,000 particles at different FFUs air speeds ranging from 0.02 to $0.75 \mathrm{~m} / \mathrm{s}$ and counted the number of trapped particles at each speed. Two opposing dependencies were observed: first, the higher the air speed, the lower the number of undetermined particles; and second, the higher the air speed, the higher the number of trapped particles on the conveyor. These dependencies were indirectly confirmed by a report from an operating technician at the factory that the level of contamination increased as the FFUs air speed was set higher than $0.70 \mathrm{~m} / \mathrm{s}$. As an example, it can be seen in Figure 7 that when the FFUs air speed was set at a typical air speed in a clean room of $0.02 \mathrm{~m} / \mathrm{s}$, only $0.48 \%$ of the released particles got trapped on the conveyor while $46.42 \%$ of them were left suspended in the airstream above the AAM, and they would either fall down onto the conveyor or get purged out of the microenvironment. Undetermined means the particle is yet unknown whether it will drop onto the conveyor, float out, or still remain inside the AAM. On the other hand, when the FFUs air speed was set at $0.50 \mathrm{~m} / \mathrm{s}$, $6.64 \%$ of the released particles got trapped while only $3.08 \%$ were undetermined. This trend seems to indicate that a lower air speed was unequivocally better; however, airflow at a lower speed was not as capable at blocking out particles from intruding into the microenvironment.

To see how the level of contamination on the conveyor was higher at a higher FFUs air speed setting, we plotted the air velocity vectors and traces of 300 particles released from random locations on the AAM at different FFUs air speeds. Figure 8 shows color-coded graphic results of the simulated particle traces at two different FFUs air speeds. At a very low FFUs air speed of $0.15 \mathrm{~m} / \mathrm{s}$, the velocities of the airstreams above pushing down on the released particles to the conveyor were not much higher than those in its immediate surrounding, so the particles were pushed down only relatively lightly; that is, the directions of some of the particle traces were downward but most were lateral as can be seen in Figure 8(a). In contrast, at a very high FFUs air speed of $0.75 \mathrm{~m} / \mathrm{s}$ as shown in Figure 8(b), the velocities of the airstreams moving downward were much higher than those in the immediate vicinity of the conveyor; therefore, the particles got pushed down harder onto the conveyor; that is, the directions of the traces of a larger number of particles were much steeper downward, so the released particles were more likely to get pushed down onto the conveyor and contaminate it.

Based on these simulation results and several guidelines for setting a proper FFUs air speed in a clean room $[1,31]$, we recommended a new optimal FFUs air speed range of $0.35-0.65 \mathrm{~m} / \mathrm{s}$ as a better choice than the $0.50-0.70 \mathrm{~m} / \mathrm{s}$ range previously implemented at the factory. A higher air speed would waste more energy without providing any less contamination.

4.2. Optimum FFUs Air Speed: Blocking Out Particles. We also wanted to know whether the airflow from the FFUs in this optimal speed range of $0.35-0.65 \mathrm{~m} / \mathrm{s}$ would be able to block particles from entering into the AAM microenvironment, hence we simulated releases of particles moving into the microenvironment from the outside at a typical air speed observed in a production scenario in which a few technicians were moving around and speaking to each other. In order to estimate such speed, we measured the air speeds from a technician breathing and speaking repeatedly for 100 times and found that those speeds were in the range of $0.12-0.26 \mathrm{~m} / \mathrm{s}$. Knowing this, we simulated the worst case: one hundred aluminum particles moving into the AAM environment in random directions at all four sides at a speed of $0.26 \mathrm{~m} / \mathrm{s}$ against the airstream from the FFUs at a speed of $0.35 \mathrm{~m} / \mathrm{s}$. The results depicted in Figure 9 show that most of the particles got blown away before they were able to enter the microenvironment, and even though a few of them were able to do so, they only stayed in it for an extremely short time and then got blown out. Their residence time in the microenvironment was certainly not long enough for them to penetrate sufficiently far into it to contaminate the AAM. Simulation trials were repeated with larger numbers of particles up to 500 and higher particle speeds up to $50 \mathrm{~m} / \mathrm{s}$. The results were the same for all cases: virtually all particles got blown away before they were able to intrude into the microenvironment of the AAM and none of them were able to stay in it long enough to contaminate the AAM. It was not surprising that the simulated particles were not able to penetrate deeply into the microenvironment even when their speeds were relatively high since their momentum was very small. Based on these results together with those in Section 4.1, we concluded that an airflow from the FFUs at a speed in the range of $0.35-0.65 \mathrm{~m} / \mathrm{s}$ would be able to protect the AAM from getting contaminated by airborne particles from the outside of its microenvironment.

4.3. Optimum FFUs Air Speed: Implementation Results. Before and after the factory implemented our recommended 

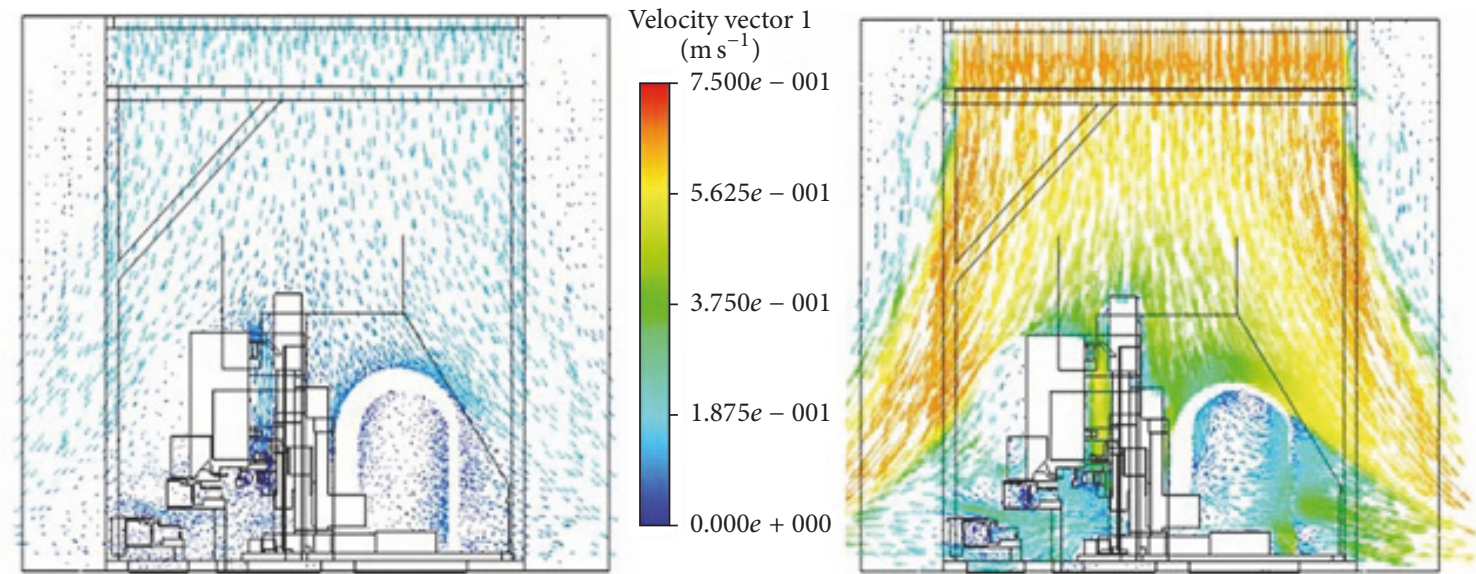

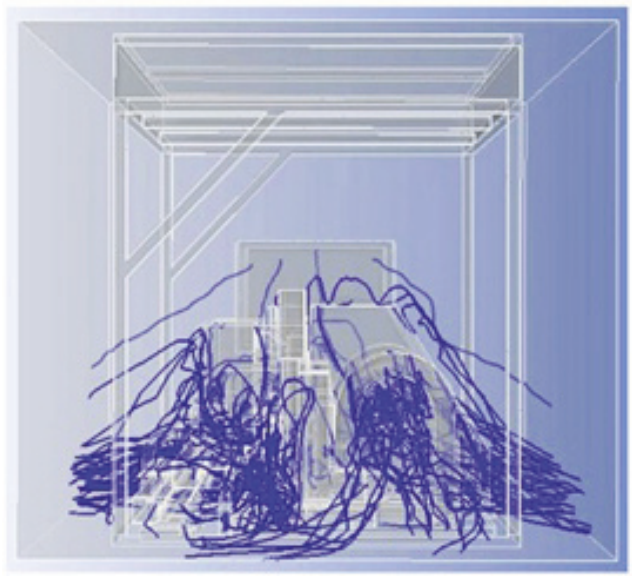

(a)

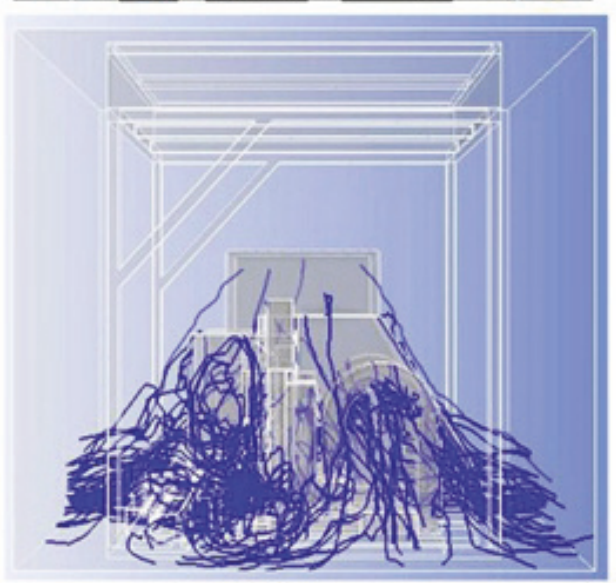

(b)

FIGURE 8: Velocity vectors and particle traces at FFUs air speed of (a) $0.15 \mathrm{~m} / \mathrm{s}$ and (b) $0.75 \mathrm{~m} / \mathrm{s}$.
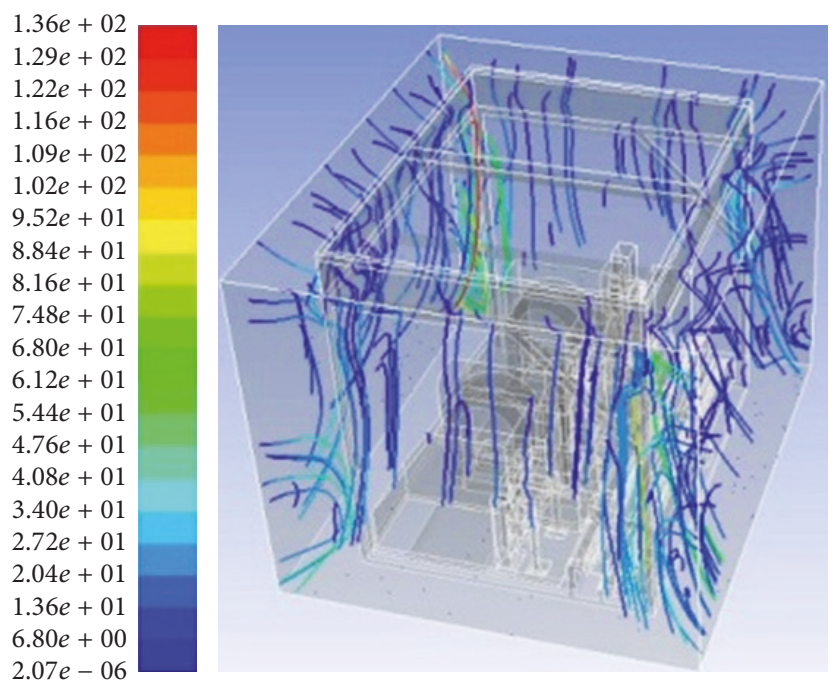

FIgURE 9: Traces of 100 incoming aluminum particles got blown away by the airflow from the FFUs at a speed of $0.35 \mathrm{~m} / \mathrm{s}$, color coded according to each particle residence time (s).

FFUs air speed range, we measured the concentration of $0.5 \mu \mathrm{m}$ particles 10 times at each of the following $6 \mathrm{key}$ locations around the AAM for a period of 1 minute each with a $\pm 10 \%$ accurate laser particle counter: locations 1,2 , and 3 on the conveyor; location 4 at the front of the AAM; location 5 at the back of the AAM; and location 6 at the walkway around the AAM (see these locations and the results in Figure 10). The significance of these measured results is as follows.

First, the airstream from the FFUs kept the concentration of particles at every key location far below the threshold level of class 1,000 clean room both before and after the air speed adjustment. Moreover, it reduced the concentration at 4 out of 6 key locations down to the threshold level of class 100 of clean room and even below that after the speed adjustment. Hence, the airstream from the FFUs at a speed in our recommended range truly augmented the capability of the class 1,000 clean room in the factory to function effectively as a class 100 clean room that was ideal for HDD production. Not shown due to limited space, concentrations of 0.3 and $5.0 \mu \mathrm{m}$ particles were also determined and found to be below the threshold level of class 1,000 of clean room.

Second, after the speed adjustment, particle concentration in every key location decreased. At the 3 locations at the conveyor, the concentrations became lower than the threshold level of class 100 clean room. Of note is that the concentration at location 4 at the front of the AAM was higher than those at location 5 at the back because there was no machine activity at the back while there were a lot of 


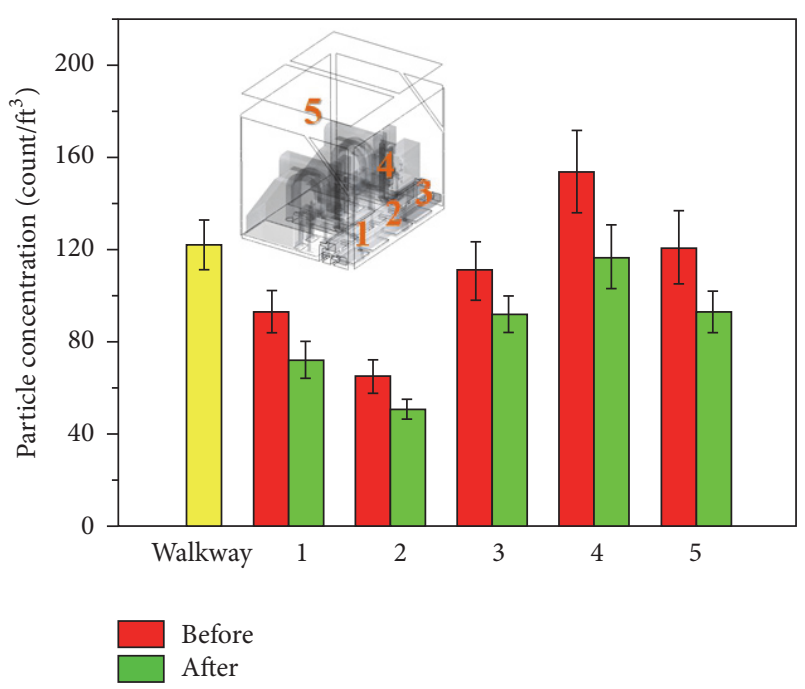

FIgURE 10: Variation in particle concentration at different comparative positions before and after FFUs air speeds were adjusted.

activities at the front. The particle concentration exceeded the threshold of class 100 clean room slightly only at location 4 .

Third, the optimal FFUs air speed range of $0.35-0.65 \mathrm{~m} / \mathrm{s}$ for the AAM that we found in this study is different from the optimum range of $0.35-0.55 \mathrm{~m} / \mathrm{s}$ found for a welding automation machine (WAM) in the previous study [25]. This might be due to the difference in the height of the FFUs above each of the two machines; the WAM and its FFUs were $27.7 \mathrm{~cm}$ farther apart than the AAM and its FFUs were. We think that an optimal FFUs air speed for any machine crucially depends on the ambient conditions of the clean room, the shape and function of the machine, and the height of the FFUs above it.

From committing field research, we found that the root cause of overcontamination resulted from the movement of the AAM that rubbed against each other and released tiny particles. The trivial cause is particles from several activities of the operators outside the AAM and the production line. The factory resolved the problem by implementing vacuum cleaners or particle suction tools into the machines to suction the particles out of the AAM machine. This method is a waste of budget and energy since it is solving the problems at the rear end which is not a sustainable solving method. Therefore, these research results not only solve problems at the causes in a sustainable and economical manner but also save costs as well.

In the factory, there were many pieces of machinery installed next to each other in the production line (Figure 1(a)), each having its own FFUs installed above it. If CFD is used to simulate the airflow above and around all of these machines, taking into account the different heights of the FFUs above them, we are fairly sure that the level of contamination can be reduced even further.

\section{Conclusion}

An automate assembly machine (AAM) used to manufacture the head stack assembly (HSA) of a hard disk drive factory met the contamination problem resulting in production of HSA that did not meet standards and needs solving. The factory required that, in the problem-solving process, all machines must not be stopped. Tools and equipment should be those that the factory already owns. Experimental methods that are simple and easy to transfer to the factory's engineers should be used. We proposed a problem solver by using the computational fluid dynamics (CFD) to simulate the airflow inside the AAM and validate the CFD results using an anemometer and sewing threads. CFD results showed the airflow and particle trace, letting us know that the air flowing out of the fan filter units (FFUs), or the FFUs air speed is in the range of $0.50-0.70 \mathrm{~m} / \mathrm{s}$. This range that the factory uses is inappropriate and is too fast resulting in contamination problems. We recommended the factory to slow the rate of the FFU's air speed down to be in the range of $0.35-0.65 \mathrm{~m} / \mathrm{s}$, which is already confirmed by the CFD analysis that this method can block out particles from outside flowing inside of the AAM, and purge away particles from the inside to the outside effectively. Accelerating the FFUs air speed over the recommended range not only causes contamination problems but also is a waste of energy. We also found that the optimal range of FFUs air speed for the AAM was not the same as those for other pieces of machinery. This was most likely due to their different shape and function as well as the different height of the FFUs above each of them. The factory adapted our recommendations for usage and found that yield was increased. The research results not also resolved the AAM contamination problems in a sustainable and economical manner but also saved energy as well.

\section{Nomenclature}

AAM: Automated assembly machine

FFU: Fan filter unit

HGA: Head gimbal assembly

$d_{p}: \quad$ Diameter of particle $(\mathrm{m})$

$F_{s}: \quad$ External force $(\mathrm{N})$

L: $\quad$ Length scale $(\mathrm{m})$

$t$ : Time (s)

$u_{p}: \quad$ Velocity of particle $(\mathrm{m} / \mathrm{s})$

$\rho_{p}: \quad$ Density of particle $\left(\mathrm{kg} / \mathrm{m}^{3}\right)$

CFD: Computational fluid dynamics

HDD: Hard disk drive

HSA: Head stack assembly

$F_{D}$ : $\quad$ Drag force $(\mathrm{N})$

g: $\quad$ Gravity $\left(\mathrm{m} / \mathrm{s}^{2}\right)$

$P: \quad$ Pressure $(\mathrm{Pa})$

$u_{f}$ : Velocity of fluid $(\mathrm{m} / \mathrm{s})$

$\rho_{f}: \quad$ Density of fluid $\left(\mathrm{kg} / \mathrm{m}^{3}\right)$

$v$ : Viscosity of fluid.

\section{Conflicts of Interest}

The author declares that there are no conflicts of interest for this article. 


\section{Acknowledgments}

This research was partially supported by College of Advanced Manufacturing Innovation (AMI) and King Mongkut's Institute of Technology Ladkrabang (KMITL).

\section{References}

[1] "Cleanrooms and Associated Controlled Environments - Part 1: Classification of Air Cleanliness," ISO No. 14644-1 (1999).

[2] G. Cao, H. Awbi, R. Yao et al., "A review of the performance of different ventilation and airflow distribution systems in buildings," Building and Environment, vol. 73, pp. 171-186, 2014.

[3] R. Flaherty, "Clean rooms: Continuing evolution of fan filter units for clean rooms," Filtration and Separation, vol. 48, no. 4, pp. 33-37, 2011.

[4] P. Naphon, S. Ratchaneekorn, and J. Kurujareon, "Heat transfer and flow characteristics in the hard disk drive tester," International Communications in Heat and Mass Transfer, vol. 36, no. 8, pp. 820-826, 2009.

[5] Y. Luan and H. Sun, "Experimental and numerical study on the resistance performance of an axial flow cyclone separator," Mathematical Problems in Engineering, vol. 2015, Article ID 384524, 2015.

[6] Z. Mo, J. Xiao, and G. Wang, "Numerical research on flow characteristics around a hydraulic turbine runner at small opening of cylindrical valve," Mathematical Problems in Engineering, vol. 2016, Article ID 6951839, 8 pages, 2016.

[7] H. K. Ma and C. H. Chen, "Development of a divided zone method for power savings in a data center," in Proceedings of the 29th Annual IEEE Semiconductor Thermal Measurement and Management Symposium, SEMI-THERM 2013, pp. 33-38, San Jose, Ca, USA, March 2013.

[8] Z. Wang and T. Ren, "Investigation of airflow and respirable dust flow behaviour above an underground bin," Powder Technology, vol. 250, pp. 103-114, 2013.

[9] L. Jiying, "A numerical study of the indoor thermal environment in an air-conditioned large space building," in Proceedings of the 8th International Conference on Intelligent Computation Technology and Automation, ICICTA 2015, pp. 69-72, Jiangxi, China, June 2015.

[10] P. V. Nielsen, "Fifty years of CFD for room air distribution," Building and Environment, vol. 91, pp. 78-90, 2015.

[11] F. Romano, L. Marocco, J. Gustén, and C. M. Joppolo, "Numerical and experimental analysis of airborne particles control in an operating theater," Building and Environment, vol. 89, pp. 369379, 2015.

[12] Y. Wang, Y. Cao, B. Liu, J. Liu, Y. Yang, and Q. Yu, "An evaluation index for the control effect of the local ventilation systems on indoor air quality in industrial buildings," Building Simulation, vol. 9, no. 6, pp. 669-676, 2016.

[13] Y. Z. Lun and P. C. Wang, "Numerical modelling of train aerodynamics in confined space," in Proceedings of the 2016 IEEE Region 10 Conference, TENCON 2016, pp. 108-115, November 2016.

[14] S.-C. Hu and C.-C. Chen, "Locating the very early smoke detector apparatus (VESDA) in vertical laminar clean rooms according to the trajectories of smoke particles," Building and Environment, vol. 42, no. 1, pp. 366-371, 2007.

[15] J. Liu, H. Wang, and W. Wen, "Numerical simulation on a horizontal airflow for airborne particles control in hospital operating room," Building and Environment, vol. 44, no. 11, pp. 2284-2289, 2009.

[16] S. Sadrizadeh, A. Tammelin, P. Ekolind, and S. Holmberg, "Influence of staff number and internal constellation on surgical site infection in an operating room," Particuology, vol. 13, no. 1, pp. 42-51, 2014.

[17] S. Sadrizadeh and S. Holmberg, "Effect of a portable ultraclean exponential airflow unit on the particle distribution in an operating room," Particuology, vol. 18, pp. 170-178, 2015.

[18] H. Liu, S. Mao, M. Li, and J. Yue, “3D Simulation for dynamic characteristics of airflow and dust control in a laneway of coal mine," in Proceedings of the 24th International Conference on Geoinformatics, Galway, Ireland, August 2016.

[19] K.-C. Noh and S.-J. Yook, "Evaluation of clean air delivery rates and operating cost effectiveness for room air cleaner and ventilation system in a small lecture room," Energy and Buildings, vol. 119, pp. 111-118, 2016.

[20] N. Liu, Q. Zhang, and K. Sundaravadivelu, "A numerical simulation of particle trajectory in thin hard disk drive," IEEE Transactions on Magnetics, vol. 49, no. 6, pp. 2590-2593, 2013.

[21] J. Thongsri and V. Pongkom, "A simulation of the number of particles trapped by the circulating filter of a hard disk drive and their trajectories," Applied Mechanics and Materials, vol. 548549, pp. 953-957, 2014.

[22] K.-C. Noh, H.-S. Kim, and M.-D. Oh, "Study on contamination control in a minienvironment inside clean room for yield enhancement based on particle concentration measurement and airflow CFD simulation," Building and Environment, vol. 45, no. 4, pp. 825-831, 2010.

[23] J. Thongsri, "A successful CFD-based solution to a water condensation problem in a hard disk drive factory," IEEE Access, vol. 5, pp. 10795-10804, 2017.

[24] M. Lee and S.-J. Yook, "Investigation of particulate contamination of heated wafers contained in a closed environment," Journal of Aerosol Science, vol. 88, pp. 148-158, 2015.

[25] J. Thongsri and M. Pimsarn, "Optimum airflow to reduce particle contamination inside welding automation machine of hard disk drive production line," International Journal of Precision Engineering and Manufacturing, vol. 16, no. 3, pp. 509-515, 2015.

[26] Turbulence, Fluent Theory Guide 17.1, 2016, Chapter 4.

[27] Multiphase Flow, Fluent Theory Guide 17.1, 2016, Chapter 17.

[28] Discrete Phase, Fluent Theory Guide 17.1, 2016, Chapter 16.

[29] R. Utikar, N. Darmawan, M. Tade et al., Hydrodynamic simulation of cyclone separators, INTECH, 2010.

[30] F. R. Menter, "Review of the shear-stress transport turbulence model experience from an industrial perspective," International Journal of Computational Fluid Dynamics, vol. 23, no. 4, pp. 305-316, 2009.

[31] T. Xu, C.-H. Lan, and M.-S. Jeng, "Performance of large fanfilter units for cleanroom applications," Building and Environment, vol. 42, no. 6, pp. 2299-2304, 2007. 


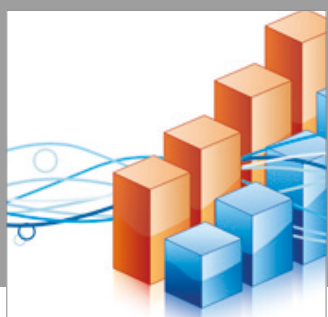

Advances in

Operations Research

vatersals

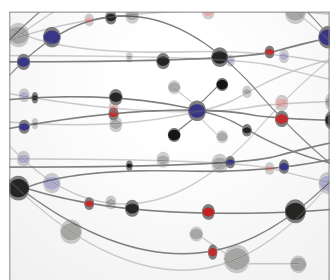

\section{The Scientific} World Journal
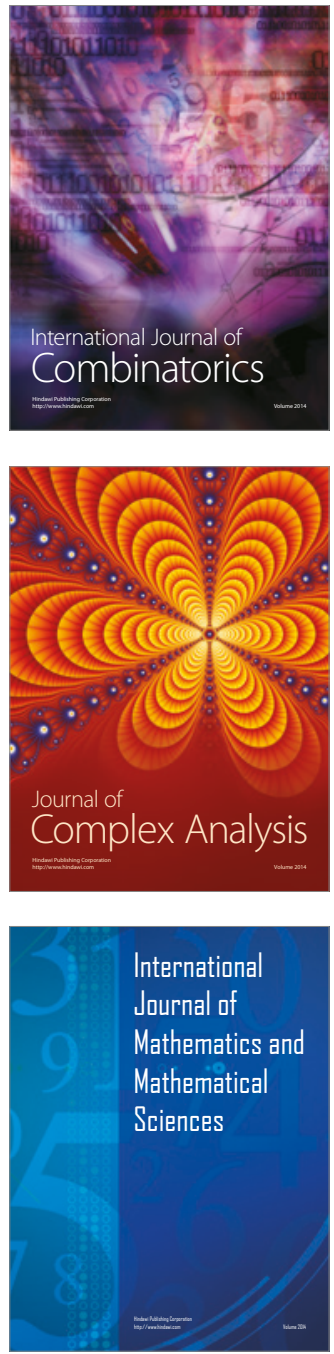
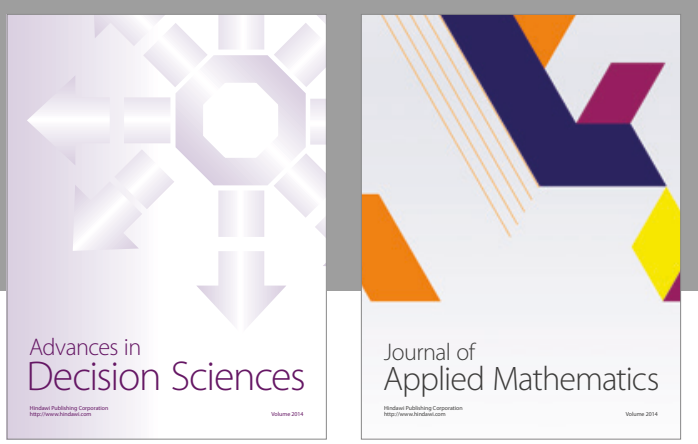

Algebra

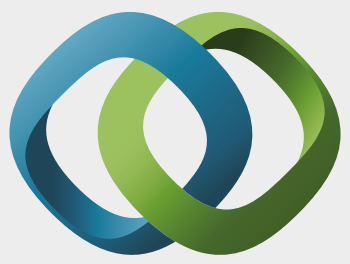

\section{Hindawi}

Submit your manuscripts at

https://www.hindawi.com
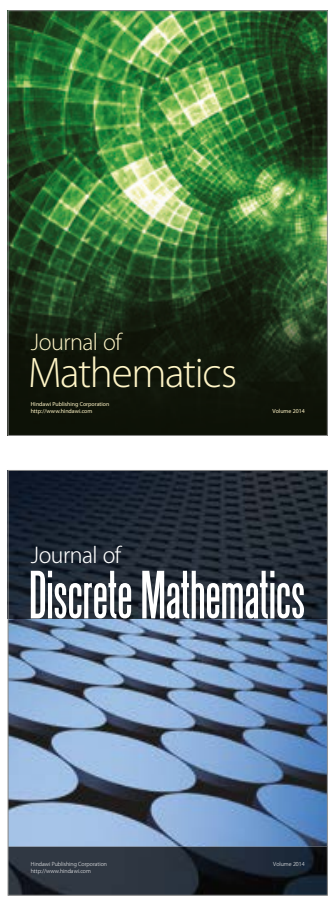

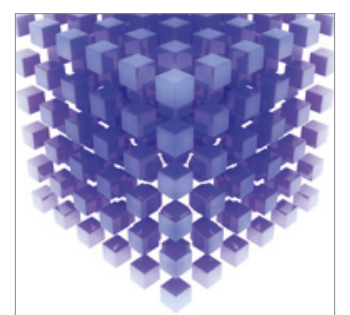

Mathematical Problems in Engineering
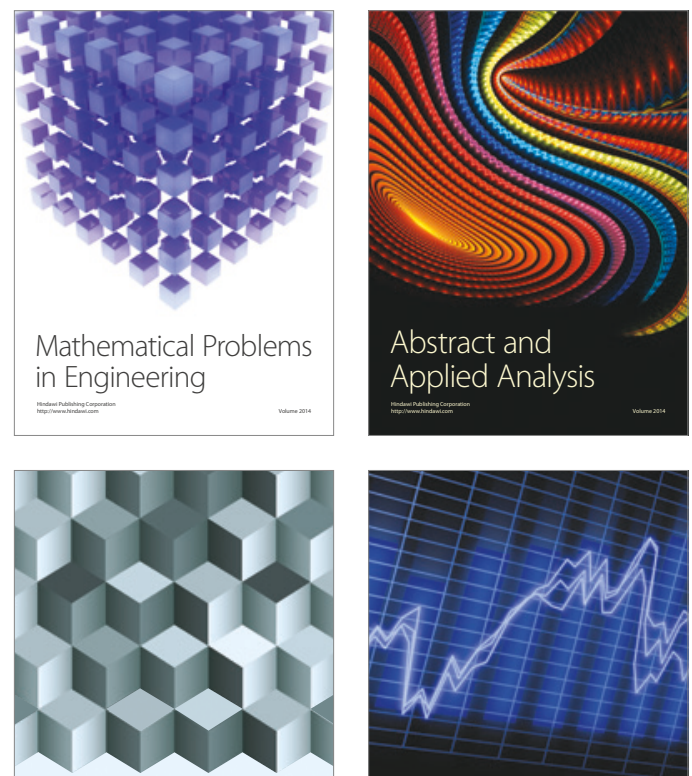

Journal of

Function Spaces

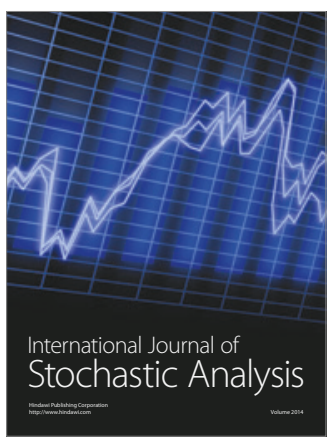

Probability and Statistics
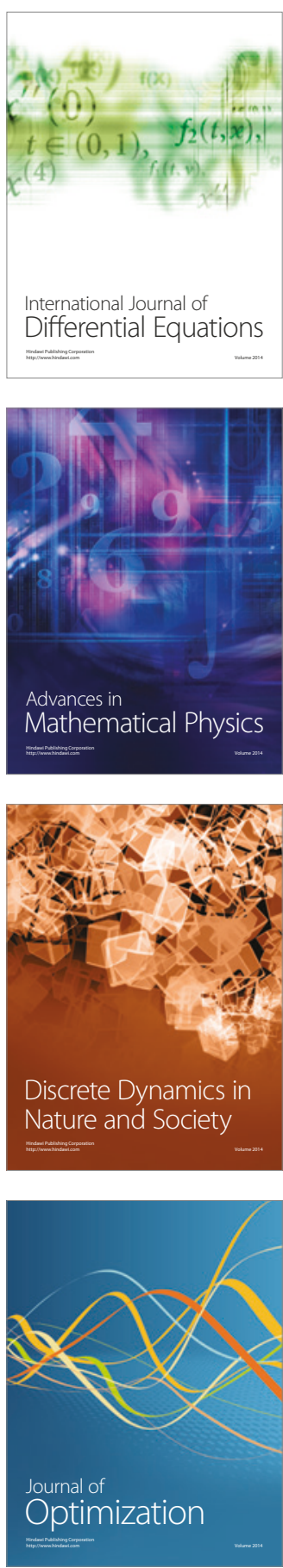